\title{
Abnormal vascular regulation in the ophthalmic artery of chronic heart failure patients
}

\section{Alteração na regulação vascular da artéria oftálmica em pacientes com insuficiência cardíaca crônica}

Daniel Meira-Freitas ${ }^{1}$, Daniela B. Almeida-Freitas ${ }^{2}$, Augusto Paranhos Jr. ${ }^{1}$

In a previous article we described findings of color Doppler imaging of ophthalmic artery in chronic heart failure (CHF) patients ${ }^{(1)}$. CHF patients presented lower blood flow velocities and higher resistance index in ophthalmic artery when compared to control group. Our research group also reported that $\mathrm{CHF}$ is associated with glaucomatous optic nerve head changes that correlate with ocular perfusion pressure (OPP) and echocardiographic parameters ${ }^{(2)}$. Herein, we expand on these findings and show the relationship between OPP and blood flow parameters of ophthalmic artery in CHF patients.

\section{METHODS}

A cross-sectional study was performed. Patients with CHF symptoms and left ventricle ejection fractions below 55\% documented by echocardiography were recruited from the outpatient heart failure clinic of the Federal University of São Paulo, Brazil. Noncardiopathic volunteers were included as a control group.

Doppler parameters of ophthalmic artery of 18 patients with CHF in different stages of disease were compared with 18 healthy volunteers (control group). Ophthalmic artery blood flow velocities were measured by transpalpebral Doppler ultrasound (EnVisor Philips, Bothell, WA, USA), with a linear high frequency transducer $(10 \mathrm{MHz})$. Participants also underwent a standardized examination that included slit-lamp biomicroscopy, gonioscopy, Goldmann applanation tonometry, and systemic blood pressure measurement. CHF patients and control subjects under 18 years of age, patients with a prior history of significant ocular disease, ocular trauma or ocular surgery, spherical equivalent greater than $\pm 4.0 \mathrm{D}$, chronic corticosteroid usage (topical or systemic), angle closure suspect, secondary glaucoma, dense media opacities, retinal disease, heart transplantation, stroke or any other neurological diseases were not included in the study.

Systolic and diastolic blood pressure readings were obtained and used to calculate the mean arterial blood pressure (MAP) according to the following formula: $\mathrm{MAP}=2 / 3^{*}$ diastolic blood pressure $+1 / 3^{*}$ systolic blood pressure. The mean OPP was calculated using the following formula: OPP $=2 / 3$ * MAP - IOP.

To take into account the correlation between both eyes of the same individual, generalized estimating equation regression was used to evaluate the relationship between the Doppler parameters of ophthalmic artery and mean OPP.

\section{RESULTS}

No age or gender differences were observed between CHF patients and controls. Mean OPP was significantly lower in CHF group than in control group $(p<0.001)$. Mean resistance index of ophthalmic artery was significantly higher in CHF group than in control group $(p=0.04)$. Figure 1 shows the relationship between the resistance index of the ophthalmic artery and the mean OPP for CHF patients and control subjects. Each decrease in $10 \mathrm{mmHg}$ in the mean OPP was associated with a 0.06 increase in the resistance index of the ophthalmic artery of CHF patients (slope $=-0.06 ; p=0.04$ ). Such correlation was not statistically significant in the control group $(p=0.48)$.

\section{COMMENTS}

The negative correlation between OPP and resistance index in CHF patients indicates an abnormal ocular vascular regulation, which is likely related to the pathophysiology of the disease. The reduction in cardiac output is associated with compensatory mechanisms

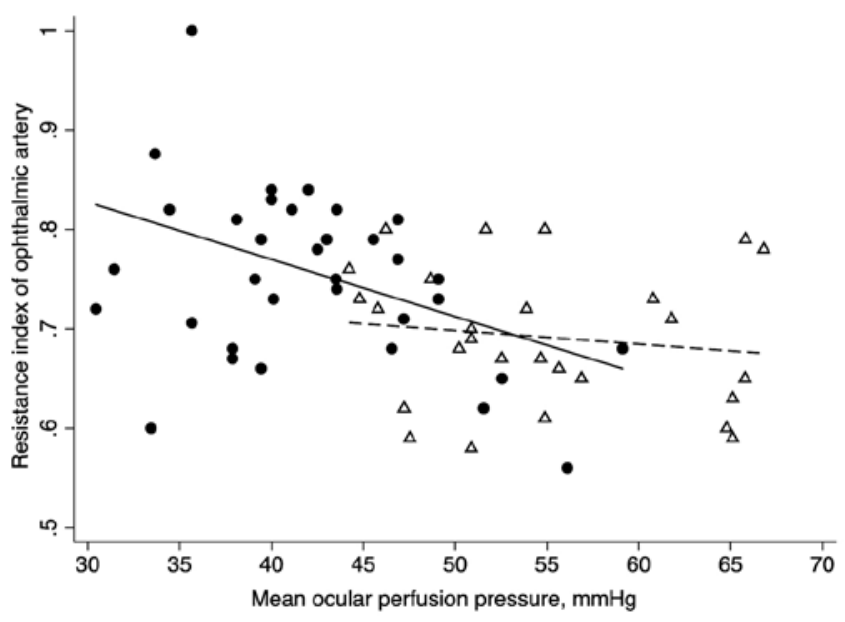

Figure 1. Relationship between resistance index of the ophthalmic artery and mean ocular perfusion pressure for chronic heart failure (CHF) patients and control subjects. Black circles and solid line correspond to $\mathrm{CHF}$ data, while hollow triangles and dashed line correspond to control group data.
Submitted for publication: April 15, 2013

Accepted for publication: April 24, 2013

${ }^{1}$ Physician, Department of Ophthalmology, Universidade Federal de São Paulo - UNIFESP - São Paulo (SP), Brazil.

2 Physician, Imaging Diagnosis Department, Universidade Federal de São Paulo - UNIFESP - São Paulo (SP), Brazil.
Funding: No specific financial support was available for this study.

Disclosure of potential conflicts of interest: D.Meira-Freitas, None; D.B.Almeida-Freitas, None; A.Paranhos Jr., None.

Correspondence address: Daniel Meira-Freitas. Department of Ophthalmology, Universidade Federal de São Paulo. Rua Botucatu, 821 - São Paulo (SP) - 04023-062 - Brazil

E-mail: freitas.daniel@gmail.com 
that include peripheral vasoconstriction in an attempt to maintain satisfactory blood pressure and perfusion to essential tissues such as the heart and brain. In CHF patients, the sympathetic and reninangiotensin systems are activated as a neurohormonal response to maintain cardiac output and hemodynamic balance ${ }^{(3)}$. However, excessive neurohormonal activity during CHF causes an increased cerebral vascular resistance, which is often accompanied by symptoms, such as cognitive dysfunction ${ }^{(4)}$. In the retrobulbar circulation, vasoconstriction may cause instability in blood flow to the optic nerve head. Ischemia followed by reperfusion is a known cause of oxidative stress and cell death by apoptosis ${ }^{(5)}$. According to this pathophysiology, patients with CHF could theoretically be exposed to hemodynamic changes in ocular microcirculation and have an increased risk for developing glaucoma. In fact, previous study have shown an association between CHF and glaucomatous optic nerve head alterations ${ }^{(2)}$

In conclusion, the abnormal relationship between resistance index of ophthalmic artery and OPP corroborates to the hypothesized vascular mechanism of the reported glaucomatous optic nerve head alterations in CHF patients. Prospective longitudinal studies are required to confirm the causal relationship between abnormal ocular blood flow and optic nerve head alterations in patients with heart failure.

\section{ACKNOWLEDGEMENTS}

The project number and institution responsible for the approval of the Research Ethics Committee is 0812/07 - UNIFESP. The authors are grateful for the financial support provided by CAPES (Coordenação de Aperfeiçoamento de Pessoal de Nível Superior) for PhD student scholarship.

\section{REFERENCES}

1. Almeida-Freitas DB, Meira-Freitas D, Melo Jr LA, Paranhos Jr A, lared W, Ajzen S. Color Doppler imaging of the ophthalmic artery in patients with chronic heart failure. Arq Bras Oftalmol [Internet]. 2011[cited 2012 Dec 21];74(5):326-9. Available from: http:// www.scielo.br/pdf/abo/v74n5/v74n5a03.pdf

2. Meira-Freitas D, Melo LA, Jr., Almeida-Freitas DB, Paranhos A, Jr. Glaucomatous optic nerve head alterations in patients with chronic heart failure. Clin Ophthalmol. 2012;6:623-9

3. Choi BR, Kim JS, Yang YJ, Park KM, Lee CW, Kim YH, et al. Factors associated with decreased cerebral blood flow in congestive heart failure secondary to idiopathic dilated cardiomyopathy. Am J Cardiol. 2006;97(9):1365-9.

4. Zuccala G, Pedone C, Cesari M, Onder G, Pahor M, Marzetti E, et al. The effects of cognitive impairment on mortality among hospitalized patients with heart failure. Am J Med. 2003;115(2):97-103. Comment in: Am J Med. 2004;116(2):137-8; author reply 138 .

5. Harris A, Rechtman E, Siesky B, Jonescu-Cuypers C, McCranor L, Garzozi HJ. The role of optic nerve blood flow in the pathogenesis of glaucoma. Ophthalmol Clin North Am. 2005;18(3):345-53, v. 